\title{
APLICAÇÃO DO MÉTODO DE SOLUÇÃO DE PROBLEMAS A3 PARA O AUMENTO DE PRODUTIVIDADE EM UM CALL CENTER
}

\author{
APPLICATION OF A3 PROBLEM SOLVING TECHNIQUE TO INCREASE PRODUCTIVITY IN A \\ CALL CENTER
}

\author{
Jhordana Silva Donato ${ }^{1}$, Thiara Cezana Gomes ${ }^{2}$, Marcelo Albuquerque Schuster ${ }^{3}$, \\ \& Marcos Wagner Jesus Servare Junior ${ }^{4 *}$ \\ ${ }^{13} 4$ Centro Universitário Salesiano - Unisales; ${ }^{2}$ Universidade Federal do Espírito Santo

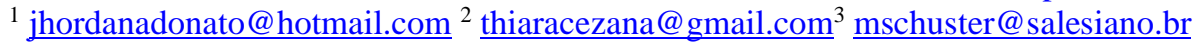 \\ 4* marcoswjunior@gmail.com
}

\section{ARTIGO INFO.}

Recebido em: 02.02.2022

Aprovado em: 21.02.2022

Disponibilizado em: 24.02.2022

Palavras-chave:

Lean; Produtividade; A3; PDCA; Desperdícios.

\section{KEYWORDS:}

Lean; Productivity; A3 Problem Solving; PDCA; Wastes.

*Autor Correspondente: Servare, M. W. J., Jr.

\section{RESUMO}

$\mathrm{O}$ Lean associado às ferramentas da qualidade e às metodologias de solução de problemas tem impulsionado empresas na busca por produtividade como diferencial competitivo de forma estratégica. Não somente investindo em mais recursos, mão de obra e capacitação, mas, também observando os problemas que estão integrados aos processos e como esses podem ser resolvidos de forma reduzir lead time. Através da ferramenta A3 Solução de Problemas e o método PDCA é possível investigar as causas-efeitos e as causas raízes dos problemas, buscando mitigar os desperdícios e aumentando a produtividade. Esse estudo de caso utilizou essa ferramenta, que passa pelas etapas de planejamento, execução, checagem e ação, e teve como objetivo atingir a meta de um dos principais indicadores do processo, o Tempo Médio de Atendimento (TMA), que tem como meta seis minutos e 50 segundos, refletindo diretamente na produtividade da operação. Aplicado em um processo de abertura de atendimento em um call center, situada na cidade de Vila Velha/ES, a empresa possui em média 200 agentes de atendimento. Com a aplicação da metodologia houve ganho médio de dois minutos e 14 segundos na chamada e um custo evitado de R\$ 0,27 centavos por chamada, totalizando, em média, 16 mil reais no período de um mês.

\begin{abstract}
Lean associated with quality tools and problem solving methodology has driven companies in the search for productivity as a strategic differential. Not investing more resources, manpower and training, but also analyzing the problems they are working on and how these can be solved in a lead time manner. Through the A3 Problem Solving tool and the PDCA method, it is possible to investigate causes-effects and causes of problems, seeking to mitigate problems, increasing profitability. This case study used this objective, which goes through the stages of planning, execution, verification and action, and was able to achieve the goal of one of the main tools of the process, the Average Service Time (TMA), which has a goal of six minutes and 50 seconds, reflecting directly on the productivity of the operation. Applied in a process of opening service in a call center, located in the city of Vila Velha/ES, the company has an average of 200 service agents. With the application of the methodology, there was a gain of two minutes and 14 seconds in the call, in addition to an avoided cost of 0.27 cents per call, totaling, on average, 16 thousand reais in a period of one month.
\end{abstract}


Citação (APA): Donato, J. S., Gomes, T. C., Schuster, M. A., \& Servare, M. W. J., Jr. (2022). Aplicação do método de solução de problemas A3 para o aumento de produtividade em um call center. Brazilian Journal of Production Engineering, 8(2), Edição Especial "Ciência na Prática", 116-125.

\section{INTRODUÇÃO}

Solucionar problemas tornou-se a grande faceta do mercado globalizado, onde a competitividade se dá não somente no produto, mas em toda jornada de compra do cliente, do pedido à entrega, seja de bens tangíveis ou serviços. A solução de problemas se torna então uma estratégia de negócio para agregar valor ao fluxo de ponta a ponta e, por isso, é necessário que esta seja uma atividade sistematicamente planejada (Andrade \& Rodrigues, 2017).

De acordo com King, Lima e Costa (2014), o conceito produtividade foi introduzido e desenvolvido nas organizações com o intuito de avaliar e melhorar o desempenho delas. Sendo calculado pela razão de volume produzido pelo tempo de trabalho, a produtividade é um dos principais indicadores de empresas que buscam produzir mais com a mesma quantidade de recursos humanos. Contudo, para que um colaborador possa ter uma produtividade mais elevada também é necessário considerar os gargalos e problemas existentes, que muitas vezes estão entrelaçados dos processos mais simples aos mais complexos.

Para eliminar gargalos e problemas, as empresas utilizam filosofias, ferramentas e metodologias em suas operações, uma dessas filosofias é o Lean Manufacturing, que visa reduzir os desperdícios do processo produtivo, aumentando a qualidade e a produtividade (Ferreira, 2018).

$\mathrm{O}$ aumento de produtividade está relacionado a produtividade de cada colaborador dentro da sua jornada de trabalho, ou seja, colaboradores que produzem com mais assertividade, agregam valor no processo. Entretanto, para que um colaborador possa ter maior produtividade é necessário considerar os gargalos e problemas rotineiros existentes.

$\mathrm{Na}$ busca pela resolução sistematizada de problemas, surgiram inúmeras metodologias, dentre elas o ciclo Plan-Do-Check-Act (PDCA). Por meio do PDCA busca-se o desenvolvimento de um processo de melhoria contínua (King, Lima, \& Costa, 2014). Esta metodologia é a base da aplicação de outras metodologias como o A3 Solução de Problemas, a Metodologia de Análise de Solução de Problemas (MASP) e o Definir, Medir, Analisar, Melhorar e Controlar (DMAIC).

Essas metodologias, antes utilizadas apenas em fábricas de bens tangíveis, atualmente são disseminadas em diversas empresas, inclusive em processos de serviços. Importante ressaltar que empresas do ramo de prestação de serviços possuem alta variabilidade de demandas, fato que impacta diretamente nos custos previstos. Assim, a aplicação das ferramentas de melhoria inclui a busca por redução de custos, aumento de produtividade, automatização de processos e eliminação de desperdícios. Dessa forma, tornam-se essenciais para o crescimento sustentável e a longevidade do negócio.

O presente artigo tem por objetivo aplicar a ferramenta A3 Solução de Problemas, a fim de identificar a causa raiz da baixa produtividade e alto tempo de lead time na prestação de serviços de soluções de televendas e atendimento ao cliente, e propor melhorias que reduzam ou eliminem os desperdícios encontrados, reestabelecendo os resultados dentro da meta estipulada, otimizando o processo e agregando valor para o colaborador e cliente final. 
Citação (APA): Donato, J. S., Gomes, T. C., Schuster, M. A., \& Servare, M. W. J., Jr. (2022). Aplicação do método de solução de problemas A3 para o aumento de produtividade em um call center. Brazilian Journal of Production Engineering, 8(2), Edição Especial "Ciência na Prática", 116-125.

A estrutura desse artigo é formada por cinco seções. A primeira sendo essa introdução, que antecede a seção de fundamentação teórica. Em seguida, iniciam-se as seções que contemplam as etapas da metodologia A3 Solução de Problema, sendo a terceira seção com a contextualização do problema, desdobramento do problema e desenvolvimento da meta. $\mathrm{Na}$ quarta seção a apresentação dos resultados, análise de causa raiz, proposta de melhoria, implementação da melhoria, mensuração dos resultados e padronização. E, por fim, a quinta seção de conclusão do estudo.

\section{FUNDAMENTAÇÃO TEÓRICA}

O Lean Manufacturing, também conhecido como produção enxuta em sua tradução, busca reduzir as complexidades do processo, com foco na redução do lead time de cada atividade, reduzindo desperdícios e aumentando a competitividade (Ferreira, 2018).

Buzato, Medeiros e Servare Junior (2020) afirmam que a filosofia Lean se baseia em três fatores, independente do segmento da empresa no qual a filosofia é implementada: (i) eliminação de desperdícios, (ii) comprometimento de toda a equipe; (iii) constante busca por melhorias de processos. Sendo assim, na busca de resoluções de problemas é importante que a equipe esteja envolvida e comprometida a fim de obter e manter bons resultados.

A busca por enxergar os problemas dos processos se torna natural, pois no lean problemas são tratados sempre como oportunidades, e com a finalidade de aproveitá-las são empregadas ferramentas da qualidade com intuito de solucioná-los. Essas ferramentas visam facilitar a elaboração e compreensão de falhas dos processos, além de serem capazes de auxiliar na resolução efetiva das causas desses problemas (Leite, Reis, \& Valenca, 2017).

O A3 é uma metodologia de resolução de problemas aplicada por equipes multidisciplinares, envolvendo diálogo contínuo entre o responsável pelo processo em que o problema acontece e demais pessoas da organização (Priori \& Saurin, 2020). Almeja-se comunicar, obter consenso, resolver problemas e atingir resultados (Liker \& Meier, 2007). Esse método, adaptado da Toyota, impulsiona a melhoria contínua nas organizações, por meio da documentação precisa e sistematizada de algumas etapas. Dentre elas estão o entendimento do problema; o desdobramento do problema ou análise da situação atual; a definição da meta ou objetivo; a identificação da causa raiz; o plano de ação ou proposição de contramedidas; a medição de resultados obtidos, a verificação da eficácia e a padronização. A Figura 1 apresenta um modelo de matriz A3 baseado nas definições de Shook (2008). O relatório A3 é assim chamado devido ao tamanho do papel usado tradicionalmente em sua confecção (Anderson, et al., 2010).

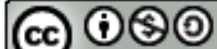


Citação (APA): Donato, J. S., Gomes, T. C., Schuster, M. A., \& Servare, M. W. J., Jr. (2022). Aplicação do método de solução de problemas A3 para o aumento de produtividade em um call center. Brazilian Journal of Production Engineering, 8(2), Edição Especial "Ciência na Prática", 116-125.

Figura 1. Matriz A3.

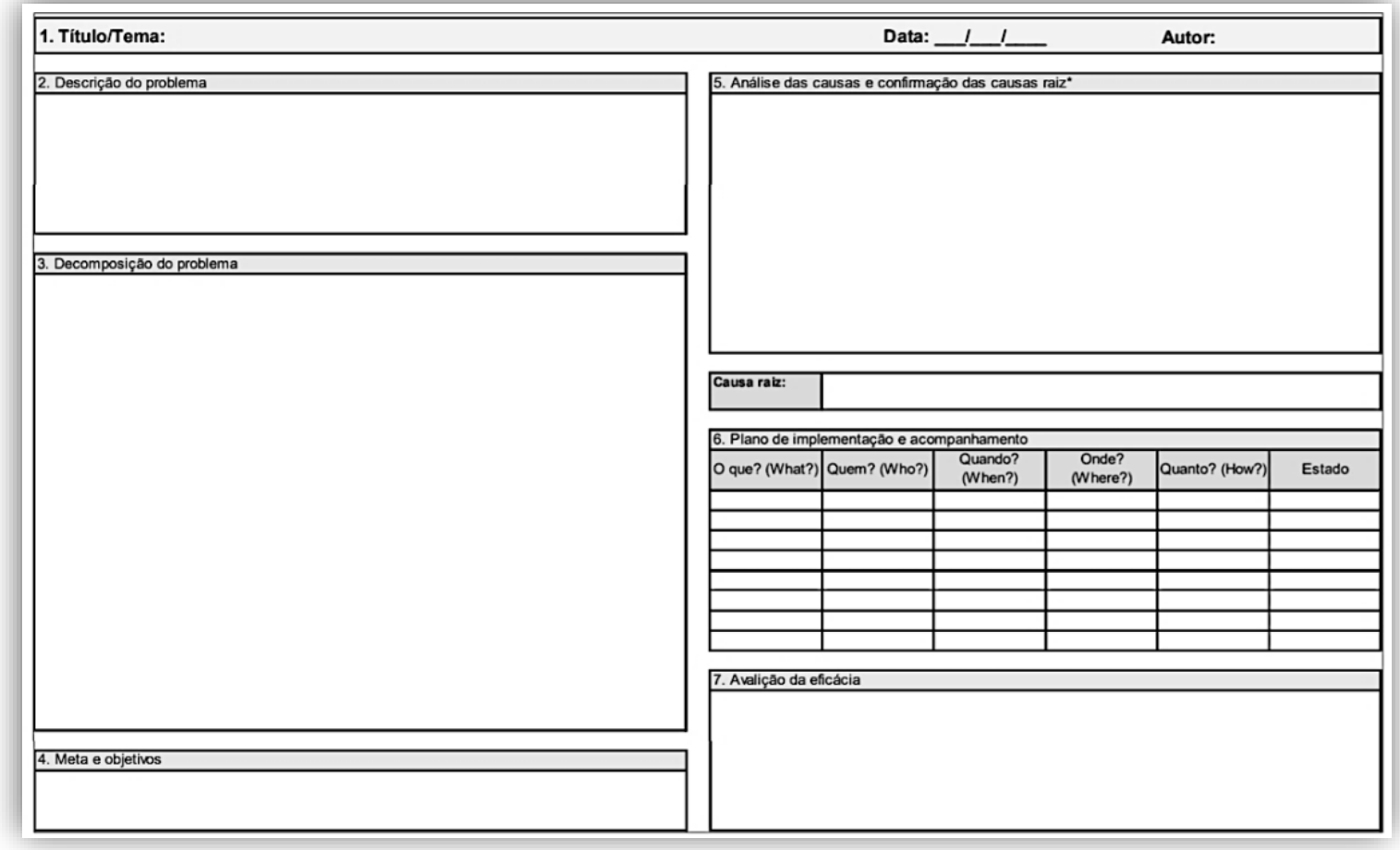

Fonte: Adaptado de Shook (2008).

É possível notar que as etapas existentes no método A3 estabelecem uma estrutura concreta para implementar a gestão do ciclo de melhoria contínua PDCA (Planejar, Executar, Controlar e Agir). Facilitando, assim, a coerência, consistência e o alinhamento interno da organização em relação ao melhor curso de ação e possibilitando o alcance de maior produtividade (Sobek II \& Smalley, 2016).

De acordo com Bassi et al. (2020), os indicadores de produtividade ajustados com os objetivos das empresas levam a outras iniciativas de melhoria em função do kaizen, por exemplo, melhoria em curto prazo e mudanças sustentadas em longo prazo. A busca por aumento de produtividade está diretamente ligada aos objetivos de redução de custo e aumento de receita das empresas que adotam a filosofia lean. As pesquisas de Done, Voss e Rytter (2011), confirmam a implantação dos indicadores de produtividade com a finalidade de sustentar os resultados obtidos a longo prazo, construindo uma base para as mudanças nas empresas. $\mathrm{O}$ acompanhamento diário é um grande aliado na manutenção de resultados obtidos por melhorias implantadas e resolução de problemas.

\section{DEFINIÇÃO DO PROBLEMA}

O estudo de caso será aplicado em uma empresa de prestação de serviços de soluções de televendas e atendimento ao cliente. A empresa situa-se na cidade de Vila Velha/ES e possui 54 anos de mercado. Um dos processos desse call center é a abertura de atendimento para assistência a vidros, peças automotivas e serviços de reparo de lataria e pintura. As empresas de call center realizam o acompanhamento de alguns indicadores importantes, que causam alto impacto em seu custo com telefonia, contratação de mão de obra, dentre outras despesas. Tendo 
Citação (APA): Donato, J. S., Gomes, T. C., Schuster, M. A., \& Servare, M. W. J., Jr. (2022). Aplicação do método de solução de problemas A3 para o aumento de produtividade em um call center. Brazilian Journal of Production Engineering, 8(2), Edição Especial "Ciência na Prática", 116-125.

como fluxo de valor a coleta e repasse de informações suficientes para atender a necessidade do cliente final.

O objeto do estudo de caso é o indicador de Tempo Médio de Atendimento (TMA), em específico, da abertura de novos atendimentos. Esse indicador mede o tempo em que o agente de atendimento inicia e finaliza a chamada com o cliente final. A meta atual da empresa é ter o seu TMA em 6 minutos e 50 segundos para abertura de novos atendimentos. Contudo, nos últimos meses a empresa não tem conseguido atingir essa meta o que gera necessidade de contratação de novos recursos e sobrecarga da atual equipe. Ainda nesse cenário, o serviço que a empresa presta é sazonal, havendo picos entre setembro e março, visto o aumento de viagens e férias dos clientes (Gráfico 1).

Gráfico 1. Histórico TMA demonstrando resultados mensais do primeiro semestre de 2021.

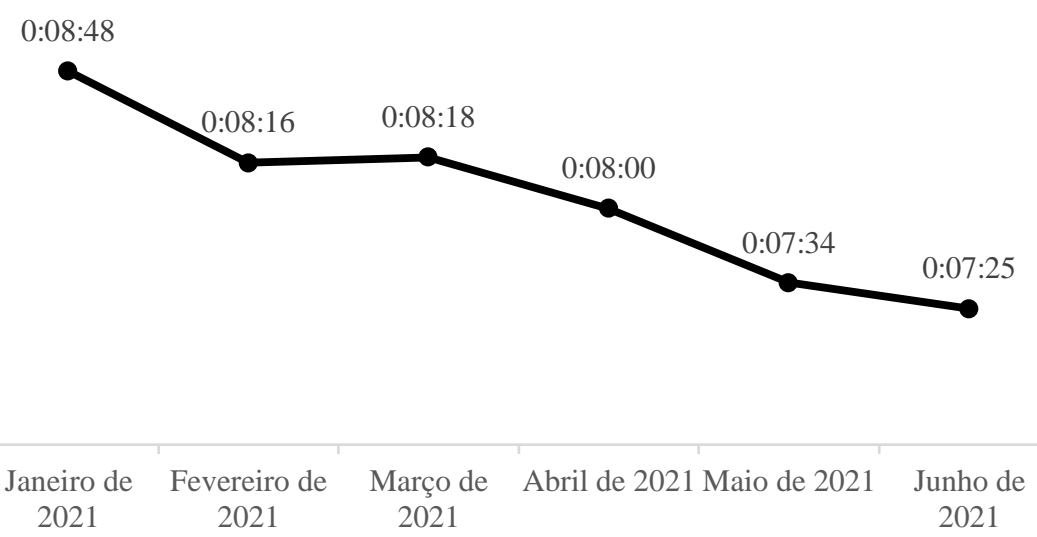

Fonte: Autores (2022).

As etapas iniciais da metodologia A3 Solução de Problemas referem-se à fase de Planejamento (P) do ciclo PDCA. Essas etapas contemplam o entendimento do problema, buscando compreender qual o estado atual do processo e qual o estado ideal em que ele deveria se encontrar. A partir dessa definição inicial, a metodologia propõe como segunda etapa o desdobramento, ou seja, pormenorizar o problema, entendendo como ele se comporta e como pode ser melhor entendido. Ainda dentro da etapa de planejamento, é estruturada a meta em que o projeto irá se basear para medir se os resultados foram positivos e se o alvo foi alcançado.

O processo de abertura de atendimento é um processo padronizado, ou seja, existem procedimentos precisos a serem seguidos pelos agentes de atendimento, de forma que todos os atendimentos sejam finalizados com as informações necessárias para as próximas etapas. Para identificação do problema foi utilizado o método Time and Motion, onde foram mapeadas todas as etapas do processo, os tempos de processamento, desperdícios e outros gargalos identificando o fluxo de valor.

Conforme Quadro 1, são macro etapas presentes no processo de atendimento ao cliente: $(i)$ abordagem e consulta da apólice; (ii) dados do dano; (iii) levantamento e confirmação dos contatos; (iv) realização de questionário; (v) agendamento e finalização (cenário 1) ou direcionamento e finalização (cenário 2). Desdobram-se em etapas menores cada uma das macro etapas listadas anteriormente.

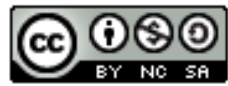


Citação (APA): Donato, J. S., Gomes, T. C., Schuster, M. A., \& Servare, M. W. J., Jr. (2022). Aplicação do método de solução de problemas A3 para o aumento de produtividade em um call center. Brazilian Journal of Production Engineering, 8(2), Edição Especial "Ciência na Prática", 116-125.

Quadro 1. Fluxo de valor.

\begin{tabular}{|c|c|c|c|c|c|c|}
\hline \multicolumn{7}{|c|}{ Abordagem e consulta da apólice } \\
\hline $\begin{array}{l}\text { Recepção do } \\
\text { atendimento }\end{array}$ & $\begin{array}{l}\text { Dados } \\
\text { pessoais }\end{array}$ & $\begin{array}{c}\text { Confirmação } \\
\text { dos dados } \\
\text { pessoais }\end{array}$ & $\begin{array}{c}\text { Data do } \\
\text { dano }\end{array}$ & $\begin{array}{l}\text { Dados do } \\
\text { veículo }\end{array}$ & $\begin{array}{c}\text { Confirmação } \\
\text { de dados do } \\
\text { veículo }\end{array}$ & $\begin{array}{l}\text { Confirmar } \\
\text { chassis }\end{array}$ \\
\hline $15 \mathrm{~s}$ & $18 \mathrm{~s}$ & $25 \mathrm{~s}$ & $18 \mathrm{~s}$ & $33 \mathrm{~s}$ & $10 \mathrm{~s}$ & $26 \mathrm{~s}$ \\
\hline \multicolumn{7}{|c|}{ Dados do dano } \\
\hline Script & $\begin{array}{l}\text { Relato do } \\
\text { dano }\end{array}$ & $\begin{array}{r}\text { Confirmação } \\
\text { da }\end{array}$ & $\begin{array}{l}\text { do relato do } \\
\text { o }\end{array}$ & $\begin{array}{l}\text { Coletar } \\
\text { estado e } \\
\text { município }\end{array}$ & & $\begin{array}{l}\text { Coleta de } \\
\text { CEP }\end{array}$ \\
\hline $7 \mathrm{~s}$ & $18 \mathrm{~s}$ & 6 & & $16 \mathrm{~s}$ & & $18 \mathrm{~s}$ \\
\hline \multicolumn{7}{|c|}{ Contatos } \\
\hline Coleta de telefone & $\begin{array}{l}\text { Confirmação } \\
\text { de telefone }\end{array}$ & $\begin{array}{l}\text { Coleta de } \\
e \text {-mail }\end{array}$ & Confirmaç: & o de $e$-mail & \multicolumn{2}{|c|}{$\begin{array}{l}\text { Registro sobre o } \\
\text { WhatsApp }\end{array}$} \\
\hline $33 \mathrm{~s}$ & $6 s$ & $28 \mathrm{~s}$ & & & $13 \mathrm{~s}$ & \\
\hline \multicolumn{7}{|c|}{ Questionário } \\
\hline \multirow{2}{*}{\multicolumn{3}{|c|}{$\begin{array}{l}\text { Questionário } \\
\text { 29s }\end{array}$}} & \multicolumn{4}{|c|}{ Informa protocolo e franquia } \\
\hline & & & & & $6 \mathrm{~s}$ & \\
\hline \multicolumn{7}{|c|}{ Agendamento e Finalização - Cenário 1} \\
\hline \multicolumn{3}{|c|}{ Agendamento } & \multicolumn{4}{|c|}{ Script final } \\
\hline \multicolumn{3}{|c|}{$25 \mathrm{~s}$} & \multicolumn{4}{|c|}{$55 \mathrm{~s}$} \\
\hline \multicolumn{7}{|c|}{ Direcionamento e Finalização - Cenário 2} \\
\hline \multicolumn{3}{|c|}{ Direcionamento } & \multicolumn{4}{|c|}{ Script final } \\
\hline \multicolumn{3}{|c|}{1 min e $3 \mathrm{~s}$} & \multicolumn{4}{|c|}{$55 \mathrm{~s}$} \\
\hline \multicolumn{3}{|c|}{$\begin{array}{l}\text { Abertura com agendamento } \\
7 \mathrm{~min} \mathrm{e} 8 \mathrm{~s}\end{array}$} & \multicolumn{4}{|c|}{ Abertura com direcionamento } \\
\hline
\end{tabular}

Fonte: Autores (2022).

Assim, a partir da análise do histórico de anos anteriores foi possível constatar que o TMA de 6 minutos e 50 segundos já foi realizado, sendo esse um valor factível. Dessa forma, definiu-se como meta do A3: "Alcançar o TMA de 6 minutos e 50 segundos no período de sazonalidade entre setembro e fevereiro".

\section{RESULTADOS E ANÁLISES}

\subsection{ANÁLISE DA CAUSA RAIZ E PROPOSIÇÃO DE MELHORIAS}

A etapa de desenvolvimento é composta pelo estudo aprofundado do processo para que seja encontrada a causa raiz do problema, associado a fase de execução do PDCA com a proposição de melhorias para que essa seja resolvida de modo eficaz. Já nesta etapa, é possível levantar resultados iniciais das análises realizadas o que gera insumo para outros estudos e planos de ação.

Após ser realizado o Time and Motion, realizou-se um brainstorming junto aos colaboradores, no qual foi possível realizar um detalhamento de cada etapa. Com isso, foram levantados os seguintes pontos de atenção:

(i) A etapa de recepção do atendimento ao cliente tende a passar muitas informações que são solicitadas novamente durante o fluxo, gerando repetição de dados;

(ii) Existem muitas etapas de confirmação de dados, mesmo sendo claras e suficientes;

(iii) $\mathrm{Na}$ etapa de solicitação da data que ocorreu o dano há um processamento excessivo da informação exata que não agrega valor;

(iv) O script de solicitação do chassi não é proativo, gerando demora no atendimento;

(v) A solicitação do perímetro (urbano ou rodoviário) é uma informação não utilizada nos processos posteriores; 
Citação (APA): Donato, J. S., Gomes, T. C., Schuster, M. A., \& Servare, M. W. J., Jr. (2022). Aplicação do método de solução de problemas A3 para o aumento de produtividade em um call center. Brazilian Journal of Production Engineering, 8(2), Edição Especial "Ciência na Prática", 116-125.

(vi) O script de solicitação de contato é longo;

(vii) O script final possui informações demasiadas.

Após o brainstorming, notou-se que a causa raiz era o processo oneroso, composto por muitas solicitações desnecessárias e etapas defasadas que não atendiam a real necessidade do cliente e da operação. A partir da identificação da causa raiz foram definidas melhorias a serem aplicadas a cada uma das macro etapas do processo estudado (Quadro 2).

Quadro 2. Proposição de melhorias.

\begin{tabular}{|c|c|c|}
\hline Etapa & Melhoria & $\begin{array}{l}\text { Desperdício reduzido } \\
\text { ou eliminado }\end{array}$ \\
\hline \multicolumn{3}{|c|}{ Abordagem e Consulta da apólice } \\
\hline Saudação inicial & $\begin{array}{l}\text { Se o cliente informar o que ocorreu anotar o relato em seu } \\
\text { bloco de notas. }\end{array}$ & $\begin{array}{l}\text { Processamento } \\
\text { Excessivo }\end{array}$ \\
\hline Dados pessoais & $\begin{array}{l}\text { O cliente deverá confirmar o primeiro e último nome do } \\
\text { segurado e o modelo do veículo. O agente deverá confirmar } \\
\text { o final do chassi e o final da placa. }\end{array}$ & Superprodução \\
\hline Data do dano & $\begin{array}{l}\text { Perguntar de imediato ao cliente se ele tem a data ainda que } \\
\text { aproximada em que ocorreu o dano. }\end{array}$ & Defeito \\
\hline Confirmar o chassi & $\begin{array}{l}\text { Não será mais necessário solicitar se está com o documento } \\
\text { em mãos. }\end{array} \begin{array}{l}\text { Confirmar os } 6 \text { últimos dígitos do chassi proativamente. }\end{array}$ & $\begin{array}{l}\text { Processamento } \\
\text { Excessivo }\end{array}$ \\
\hline \multicolumn{3}{|c|}{ Dados do Dano } \\
\hline & Confirmar qual peça está danificada de forma objetiva. & $\begin{array}{l}\text { Processamento } \\
\text { Excessivo }\end{array}$ \\
\hline Script & $\begin{array}{l}\text { Muitas vezes o cliente informa a peça no início da ligação. } \\
\text { Anote no bloco de notas e só confirme, não repita a pergunta: } \\
\text { "Para qual item deseja atendimento?". }\end{array}$ & Defeito \\
\hline Relato do dano & $\begin{array}{c}\text { Copiar e colar em seu bloco de notas o relato do dano } \\
\text { informado pelo cliente. }\end{array}$ & $\begin{array}{l}\text { Processamento } \\
\text { Excessivo }\end{array}$ \\
\hline CEP & $\begin{array}{c}\text { O CEP não deve ser questionado nessa aba. Deverá } \\
\text { questionará na aba "direcionamento". }\end{array}$ & $\begin{array}{l}\text { Processamento } \\
\text { Excessivo }\end{array}$ \\
\hline Perímetro & $\begin{array}{c}\text { Não é mais necessário questionar se o perímetro é urbano ou } \\
\text { rodoviário ao cliente. }\end{array}$ & Superprodução \\
\hline \multicolumn{3}{|c|}{ Contatos } \\
\hline Coleta de telefone & $\begin{array}{l}\text { Questionar ao cliente somente se "pode informar telefone de } \\
\text { contato com DDD". }\end{array}$ & $\begin{array}{l}\text { Processamento } \\
\text { Excessivo }\end{array}$ \\
\hline Coleta de $e$-mail & $\begin{array}{l}\text { Se o } e \text {-mail for de fácil compreensão não há necessidade de } \\
\text { realizar o eco. } \\
\text { Se ficar claro que o } e \text {-mail pertence ao corretor ou ao } \\
\text { segurado também não realize a pergunta a quem pertence o } e \text { - } \\
\text { mail. }\end{array}$ & $\begin{array}{l}\text { Processamento } \\
\text { Excessivo }\end{array}$ \\
\hline \multicolumn{3}{|c|}{ Questionário } \\
\hline Protocolo e Franquia & Informar o Protocolo e Franquia caso haja pausa do sistema. & Espera \\
\hline \multicolumn{3}{|c|}{ Agendamento e Finalização } \\
\hline Agendamento & $\begin{array}{l}\text { Não questionar se o cliente deseja ser informado dos dados da } \\
\text { loja em linha. Reforçar somente que as informações serão } \\
\text { enviadas por } e \text {-mail e SMS. }\end{array}$ & $\begin{array}{l}\text { Processamento } \\
\text { Excessivo }\end{array}$ \\
\hline Script Final & $\begin{array}{c}\text { Ao finalizar não informar o 0800, pois o cliente ligou para o } \\
\text { número, portanto ele já sabe da informação. }\end{array}$ & $\begin{array}{l}\text { Processamento } \\
\text { Excessivo }\end{array}$ \\
\hline \multicolumn{3}{|c|}{ Processo Completo } \\
\hline Confirmações & $\begin{array}{l}\text { Não é necessária a confirmação de todos os dados logo após } \\
\text { serem passados, somente em caso de dúvida do agente. }\end{array}$ & $\begin{array}{l}\text { Processamento } \\
\text { Excessivo }\end{array}$ \\
\hline
\end{tabular}

Fonte: Autores (2022).

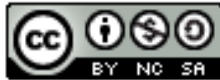


Citação (APA): Donato, J. S., Gomes, T. C., Schuster, M. A., \& Servare, M. W. J., Jr. (2022). Aplicação do método de solução de problemas A3 para o aumento de produtividade em um call center. Brazilian Journal of Production Engineering, 8(2), Edição Especial "Ciência na Prática", 116-125.

De posse das informações elencadas no Quadro 2, elaborou-se o plano de ação a ser implementado, conforme Quadro 3. Para isso, fez-se uso da ferramenta 5W2H, no qual as ações são planejadas utilizando sete perguntas chaves: What? (O que?), When? (Quando?), Why? (Porquê?), Where? (Onde?), Who? (Quem), How? (Como?), How much? (Quanto?). O procedimento mantém perguntas e respostas dispostas em uma tabela.

Quadro 3. Plano de Ação.

\begin{tabular}{|c|c|c|c|c|c|c|}
\hline \multicolumn{7}{|c|}{ Plano de Ação - 5W2H } \\
\hline O que? (What?) & $\begin{array}{l}\text { Quando? } \\
\text { (When?) }\end{array}$ & $\begin{array}{l}\text { Quem? } \\
\text { (Who?) }\end{array}$ & Por quê? (Why?) & $\begin{array}{c}\text { Onde? } \\
\text { (Where?) }\end{array}$ & Como? (How?) & $\begin{array}{l}\text { Quanto? } \\
\text { (How } \\
\text { Much?) }\end{array}$ \\
\hline $\begin{array}{c}\text { Capacitar os agentes } \\
\text { no novo fluxo }\end{array}$ & Agosto & $\begin{array}{l}\text { Autor e } \\
\text { empresa }\end{array}$ & $\begin{array}{c}\text { Para mudança do } \\
\text { fluxo }\end{array}$ & Teams & Treinamento & - \\
\hline $\begin{array}{c}\text { Realizar ponto de } \\
\text { controle com a } \\
\text { liderança }\end{array}$ & Semanal & $\begin{array}{l}\text { Autor e } \\
\text { empresa }\end{array}$ & $\begin{array}{c}\text { Para controle e } \\
\text { motivação }\end{array}$ & Teams & Reunião & $\begin{array}{c}\text { 1x na } \\
\text { semana }\end{array}$ \\
\hline $\begin{array}{l}\text { Acompanhar os } \\
\text { resultados }\end{array}$ & Ago/Set/Out & $\begin{array}{l}\text { Autor e } \\
\text { empresa }\end{array}$ & $\begin{array}{l}\text { Para mensurar os } \\
\text { resultados }\end{array}$ & Excel & $\begin{array}{l}\text { Compilação de } \\
\text { Resultados }\end{array}$ & - \\
\hline
\end{tabular}

Fonte: Autores (2022).

\subsection{IMPLANTAÇÃO, VERIFICAÇÃO DA EFICÁCIA E PADRONIZAÇÃO}

Identificada a causa raiz, levantadas as propostas de melhoria e elencadas as ações, a próxima etapa prevista na metodologia A3 é a implementação dessas ações, a mensuração dos resultados e a padronização do novo processo, caso os resultados tenham sido positivos. Se a meta não for alcançada, a metodologia prevê reiniciar o ciclo PDCA.

Após a execução dos passos listados anteriormente no processo de soluções de televendas e atendimento ao cliente, notou-se que a meta proposta de alcançar o TMA de 6 minutos e 50 segundos foi atingida logo no primeiro mês de aplicação das melhorias, conforme Gráfico 2. Além do ganho no histórico anual, em comparação ao mesmo período do ano anterior, do qual o comparativo se torna mais eficaz devido sazonalidade o ganho foi de 2 horas e 14 minutos na média.

Gráfico 2. Ganhos de TMA.

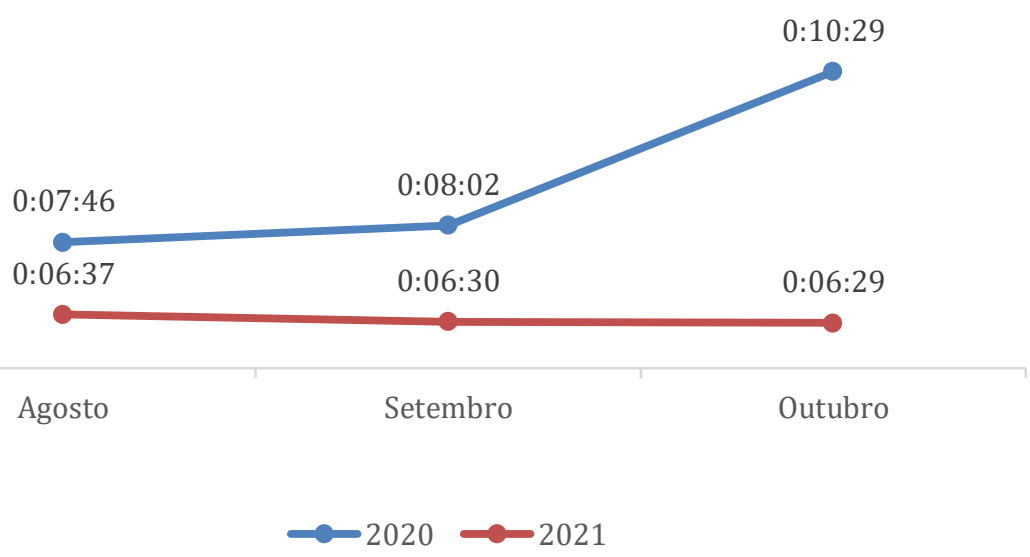

Fonte: Autores (2022). 
Citação (APA): Donato, J. S., Gomes, T. C., Schuster, M. A., \& Servare, M. W. J., Jr. (2022). Aplicação do método de solução de problemas A3 para o aumento de produtividade em um call center. Brazilian Journal of Production Engineering, 8(2), Edição Especial "Ciência na Prática", 116-125.

Na empresa de estudo o custo de telefonia é calculado por minuto falado, deste modo em 2020 o custo médio por chamada era de $\mathrm{R} \$ 1,03$ e em 2021 por meio das melhorias propostas e executadas esse custo caiu para $\mathrm{R} \$ 0,76$, ou seja, uma redução de $\mathrm{R} \$ 0,27$, conforme Gráfico 3. Ao considerar que a empresa recebe, em média, 60 mil chamadas por mês isso gera um impacto de $\mathrm{R} \$ 16.200,00$ em custo evitado.

Gráfico 3. Ganhos Custo em Telefonia.
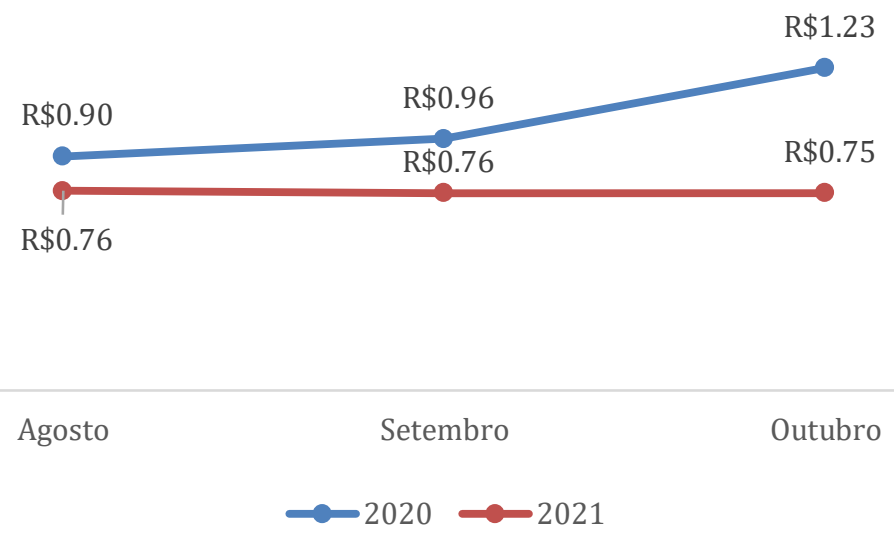

Fonte: Autores (2022).

Uma vez verificada a validade e a eficácia das ações, aplicou-se a padronização do processo melhorado. Para padronização, a empresa utilizou uma base de conhecimento, onde registra por Instrução de Trabalho (IT) as etapas e instruções necessárias para que todos conduzam o processo da mesma forma. Logo, foi utilizada uma ferramenta já existente na empresa.

\section{CONCLUSÃO}

A busca pelo aumento de produtividade passa por questões abrangentes e específicas, incluindo desde a contratação do perfil adequado para a função à um processo apropriado para obtenção de resultados esperados. Sendo assim, trata-se de um assunto complexo, mas não impossível de ser realizado. O estudo demonstrou que com análise de dados, boa gestão do processo, aplicação de ferramentas corretas, entendimento de fluxo de valor e da jornada do cliente, é possível entregar ao cliente final aquilo que ele precisa e espera, sem gerar super processamento de dados, movimentação excessiva de telas e tempo inutilizado.

Logo, considera-se que a metodologia A3 se apresentou aplicável ao estudo para aumento de produtividade em um processo de bem não-tangível. Os resultados demonstraram eficácia e aumento na geração de valor tanto para os clientes finais quanto para os colaboradores.

Com a eliminação dos desperdícios encontrados por meio da aplicação do Time and Motion ficou evidenciado que o processo continha pontos de melhoria, de fácil aplicação e que iriam gerar resultados imediatos. Com isso, além do ganho de processo com aumento de produtividade e dos ganhos financeiros, observou-se durante o estudo aumento da interação dos envolvidos e o direcionamento de foco para um processo que é de extrema criticidade para a empresa.

A partir desse cenário, outros estudos podem ser realizados para aprofundamento da temática, por exemplo: replicar a metodologia em outros processos, visto que sempre existem 
Citação (APA): Donato, J. S., Gomes, T. C., Schuster, M. A., \& Servare, M. W. J., Jr. (2022). Aplicação do método de solução de problemas A3 para o aumento de produtividade em um call center. Brazilian Journal of Production Engineering, 8(2), Edição Especial "Ciência na Prática", 116-125.

desperdícios que podem ser reduzidos e/ou eliminados em uma organização; métodos específicos para novos agentes que possuem uma curva de aprendizagem alta que impacta no TMA; aplicação do método DMAIC que busca reduzir a variabilidade para uniformizar os resultados de agentes em demais situações; uso do método Desing Thinking que busca observar e criar protótipos, com intuito de obter outras soluções para os problemas encontrados. É notório que estudos no âmbito da prestação de serviços ainda possuem grandes oportunidades de avanço quanto aos métodos de resolução de problemas, podendo gerar muitos ganhos operacionais e de pesquisa e desenvolvimento.

\section{BIBLIOGRAFIA}

Anderson, J. S., Morgan, J. N., \& Williams, S. K. (2010). Using Toyota's A3 thinking for analyzing MBA business cases: Working paper series 10-02. Working Paper. NAU W.A. Franke College of Business.

Andrade, R. S. \& Rodrigues, A. (2017). Implementação da metodologia de análise e solução de problemas (MASP) para redução de perdas em empresas manufatureiras. Revista da Universidade Vale do Rio Verde, 15(1),73-82. Recuperado de http://periodicos.unincor.br/index.php/revistaunincor/article/view/3784

Bassi, E., Oliveira V., de, C. M., Amaral, C. S. T., \& Campanini, L. (2020). Fatores de sustentação dos resultados do kaizen na produtividade: estudo de caso múltiplo. Revista Produção Online, 20(1), 275-295. 2 Recuperado de https://www.producaoonline.org.br/rpo/article/view/3523

Buzatto, N. C., Medeiros, M. L., de, \& Servare, M. W. J., Jr. (2020). Aplicação da filosofia lean em pequenas e médias empresas: revisão bibliográfica. Brazilian Journal of Production Engineering-BJPE, 29-37. Recuperado de https://periodicos.ufes.br/bjpe/article/view/27570

Done, A., Voss, C. A., \& Rytter, N. G. (2011). Best practice interventions: short-term impact and long-term outcomes. Journal of Operations Management, 29(5), 500-513.

Ferreira, R. (2018). Sistemas Lean. Volume 1. $1^{\circ}$ Edição. Belo Horizonte - MG: Poisson.

King, N. C. D. O., Lima, E. P. D., \& Costa, S. E. G. D. (2014). Produtividade sistêmica: conceitos e aplicações. Production, 24, 160-176. Recuperado de https://www.scielo.br/j/prod/a/MqJMcPzXt4vPdVNPMxyxcmq/?lang=pt

Leite, D. G., Reis, P. S. A., dos, \& Valenca, A. K. A. (2017). Aplicação das técnicas do lean seis sigma na redução do lead time de uma lavanderia industrial hospitalar. Anais do XXXVII Encontro Nacional de Engenharia de Produção. Joinville, SC. Recuperado de http://www.abepro.org.br/biblioteca/TN_STO_238_376_34836.pdf

Liker, J. K. \& Meier, D. (2007). O modelo Toyota - Manual de aplicação: um guia prático para a implementação dos 4Ps da Toyota. Porto Alegre - RS: Bookman Editora.

Priori, F. R. \& Saurin, T. A. (2020). Solução de problemas em uma emergência hospitalar: avaliação dos métodos A3 e análise de causa raiz. Revista Produção Online, 20(1), 63-94. Recuperado de https://www.producaoonline.org.br/rpo/article/view/3258

Shook, J. Gerenciando para o aprendizado: usando um processo de gerenciamento A3 para resolver problemas, promovendo alinhamento, orientar e liderar. São Paulo: Lean Institute Brasil, 2008.

Sobek II, D. K. \& Smalley, A. (2016). Entendendo o pensamento A3: um componente crítico do PDCA da Toyota. Bookman Editora. 